\title{
"EXCERPTA" DE ORATORIA ROMANA
}

Luciana Sparisci

\begin{abstract}
This article analyzes "oratory speech" as a literary, linguistic, and social phenomenon during the Pre-Ciceronian period.

The main objective is to offer a new model for analyzing Latin texts.
\end{abstract}

Entre las manifestaciones artísticas de la cultura romana, la Oratoria ocupa un lugar privilegiado. "Comunicativo" por naturaleza, el pueblo itálico paulatinamente perfecciona las técnicas del uso de la palabra oral y escrita hasta convertirla en el objeto de su "Ars Oratoria". Su evolución la examinamos no siempre en modo exhaustivo en las correspondientes etapas de la historia de la literatura latina o bien en los fragmentos o textos de los autores más o menos afortunados en la tradición de sus obras.

Sin embargo, esta prosa oratoria merece un análisis especial, porque son especiales las circunstancias que la generan, las técnicas que la dirigen y los objetivos que pretende. Sujeta a las leyes generales de la retórica, se impone por sus "estilos" particulares y genera un producto extremamente "vivo".

A la luz de nuevos enfoques es indispensable interpretar ese "estilo oratorio" no sólo como fenómeno lingü ístico y literario, sino también como fenómeno social, y analizar, entonces, tal "lenguaje" especial en calidad de manifestación de las exigencias y circunstancias de la comunicación del pueblo romano. Desde esta perspectiva, es evidente que la oratoria ofrece un vasto campo de estudio a la moderna "sociología del lenguaje".

En el marco de las contingencias históricas expondré y comentaré en este artículo, algunos momentos de la oratoria preciceroniana para ofrecer otro modelo de análisis de texto.

PERIODO DE LOS ORIGENES (...... hasta 240 a. C.)

Desde sus inicios, la república romana ofrece una clara manifestación de los ásperos conflictos internos que enturbiarán repetidamente la vida política de Roma, hasta convertirse en guerras civiles a campo abierto. Las primeras luchas se generan por el mismo planteamiento de la constitución republicana, cuya ideología fomenta la división de clase, así como por las consecuencias de las primeras acciones militares entre los mismos itálicos. La respuesta a situaciones históricas de esta naturaleza es la "rebelión" en cualesquiera de sus múltiples exteriorizaciones posibles. La clase defraudada en las actuaciones de la original "respublica romana", es obviamente la plebe. La prepotencia aristocrática, con suma osadía, programa lineamentos de una economía de la cual no puede verse aventajado quien sea pobre y carente de gentilicio. Las primeras "protestas" que conocemos de la época primiti$\mathrm{va}$, son fruto de un connubio histórico-legendario que enriquece la epopeya romana y que la historiografía posterior transmite con abundancia de datos.

Los plebeyos, desesperados por las usurpaciones, agobiados por las demás, impotentes frente al derecho de estado, buscan las primeras medidas de fuerza en acciones colectivas, o bien, apoyan la acción política del magistrado que opere en su favor y se convierta en su "héroe". En uno u otro caso, la tensión existente entre los usurpados y el estado, es dramática: es impelente, por parte de éste reducir los ciudadanos a la calma, sin que medie aún la violencia.

El arma en un pueblo históricamente comunicativo como el itálico, es la "palabra" justa o falsamente utilizada para lograr tal objetivo: ies necesario "persuadir" al pueblo en rebelión, para que desista de sus actitudes!, porque, "como siempre, 
habrá un cambio"; es justo "convencer" el senado, para lograr una distribución más equitativa de tierras entre los pobres y los aliados itálicos; ¿y quién puede operar esa persuación?, ¿quién puede mediar entre las dos clases? iNo cualquier hombre, un político cualquiera! sino quien sea bien conocido por su calidad de "verba bene dicendi", $y$, mejor, si goza de fama de "bonus" u "optimus" entre los ciudadanos de ambos bandos.

Surge, en estas circunstancias, el "discurso oratorio" latino, no cultivado, en su origen, en escuelas de retórica, sino nacido en el marco histórico de contingencias sociales. (Las escuelas se crearán; tendrán sus discípulos, pero más tarde). En sus inicios, la oratoria romana, así como Cicerón confesaba haber tenido el Foro por maestro, tendrá por maestra la misma vida política de la primera edad republicana.

Es el discurso "deliberativo", entonces, el que se abre camino y triunfará, junto con el "judicial", en la convulsionada segunda edad republicana, en que el senado será el punto de referencia de toda acción emprendida o por emprender.

Los romanos parecen estar dotados de vocación para un "discurso" del cual deba surgir un efecto inmediato: el lenguaje judicial adquiere su codificación en la segunda mitad del siglo $\mathrm{V}$ a $\mathrm{C}$., en las leyes de las XII Tablas; tal lenguaje se había experimentado entonces, desde época atrás, en exteriorizar pensamientos que sirvieran no "ad cogitandum" sino, tratándose de cuestiones legales (primitivas, pero primeras del mundo occidental) "ad vivendum", para catalogar normas de orden social.

Paralelamente, se había experimentado el lenguaje para celebrar diferentes momentos de la vida social: hay memoria de las "mortuorum laudationes", normalmente pronunciadas por un magistrado elegido del senado y conservadas en los archivos de las familias más poderosas. El elogio fúnebre tiene connotaciones peculiares: la "pietas" inspirada por el sentimiento de la muerte, enfoca el discurso en la "exaltación", inevitablemente en forma unidireccional; en la historiografía, los "elogia" se condenan, por haber corrompido la historia, "fallenti mendacio". Sin embargo, abstrayéndola de problemas de veracidad, las "laudationes" se presentan como el futuro discurso "epidictico" o de ocasión.

$\mathrm{Ni}$ el lenguaje de las XII Tablas, ni el de los elogios fúnebres es oratorio aún, pero sí lo antecede y gesta. En corto tiempo, no amparado por escuelas, se cimenta el "discurso oratorio". Y parece consecuente: "La lengua de la conversación está regida por una retórica instintiva y práctica, y usa, a su manera, procedimientos de elocuencia. Para enunciar las cosas menores, hace falta que el pensamiento se convierta en acción y se imponga por el lenguaje" (1). Oratoria instintiva, entonces, en los primeros discursos de la antigua edad republicana, que, por el buen sentido lógico del orador, debía surtir determinado efecto. Este no aprendió en la teoría, sino constató que "hace falta que el lenguaje se haga unas veces penetrante, incisivo, enérgico, obstinado; otras, vibrante, apasionado; otras, humilde y suplicante; otras, hasta hipócrita" (2). No se experimentaron inmediatamente todas las posibilidades del uso del lenguaje, pero conocieron, los antiguos romanos, la forma más natural de adueñarse de él para manejarlo en modo adecuado.

Se introduce así con maestría en la historia de la primitiva oratoria romana, la "fábula" que Menenio Agripa, en el 493 a.C. relató, a manera de discurso, para convencer a los plebeyos amotinados en el Monte Sacro: amenazaban con crear una constitución por su cuenta, oprimidos por las penas de sus deudas y la milicia. Cicerón y los historiadores antiguos analizan el episodio caracterizando al protagonista-orador, o describiendo los hechos según los respectivos objetivos. Mediador entre el senado y los plebeyos, se ofrece y es aceptado Agripa, por ser "hombre que se encontraba en el máximo vigor de la edad y parecía diferir de los demás por la agudeza del pensamiento, $y$, sobre todo, era estimado por su conducta política, pues "se mantenía en el medio sin exaltar la prepotencia de los aristócratas y sin permitir que el pueblo fuera árbitro de hacer lo que quería" (3). Retrato hablante, rendido por Dionisio, del orador, "vir bonus dicendi peritus" (4), Agripa: bonus en cuanto a sus "mores", y conocedor de alguna, si bien no académica, técnica del discurso. Hace silencio la asamblea "tanto que parece un desierto" para escuchar a Agripa, quien ..." intromissus in castra prisco illo dicendi et horrido modo... narrasse fertur" (5), no sin antes haber reflexionado que, entre otras cosas, tenía que usar las frases más persuasivas. Al concluir la exposición de la célebre fábula del vientre y los miembros del cuerpo humano, a la manera de Esopo, finaliza el texto: "Sic senatus et populus, quasi unus corpus, discordia pereunt, concordia valent". Surte el efecto deseado el "priscus orator", puesto que "Hac fabula Menenius flexit hominum mentes et plebs in urbem regressa est" (6). Convenció a la masa de los plebeyos, quienes, poco después, lograron la conquista del nombramiento de dos "tribuni plebis". 
Actúa Agripa según los canones de la retórica, pues su oratoria circunscribe la finalidad del discurso al convencimiento por inducción del oyente, mediante el "exemplum", la fábula en cuestión. "Primum oratoris officium esse dicere ad persuadendum accommodate" (7); y no de las cosas en su totalidad, se debe convencer, sino "in civilibus quaestionibus iusta et bona" (8). Así se hace necesaria la figura del "bonus" $y$ "optimus orator" para que su discurso sea el resultado de un discernimiento entre las "res" más convenientes a presentar con las "verba" adecuadas.

Decía yo en otras líneas que el lenguaje puede ser ahora penetrante, enérgico, quizás como el de Agripa, y a veces suplicante y hasta hipócrita. Pues, en la historia de la política, el suceso está íntimamente ligado a las técnicas de la oratoria; un antiguo ejemplo de esta afirmación lo ofrece, en la misma época, Spurio Casio, quien, en su tercer consulado, presentó una reforma agraria para dotar a los pobres y a los confederados de tierras. Según Dionisio y Livio, solía conquistarse la masa con estudiados discursos suaves y aduladores, y lograba convencerla: pero fue acusado de aspirar a la tiranía (es frecuente en la historia de Roma que cualquier autor de reformas agrarias sea visto, por las fuerzas opuestas, como un potencial tirano), y entonces el pueblo no se dejó más convencer por aquellas palabras que él "había conjuntamente ordenado para sus fines" (9).

Las acciones políticas y militares romanas a veces son rápidas, a veces lentas; el senado también incurre en vacilaciones o en errores tácticos: valiosa es entonces la intervención de "orationes"; éstas se elevan solemnes y austeras como "vox populi romani", ora para aplaudir, ora para condenar las actuaciones.

En el 280 a. C., Apio Claudio, testimonio de las guerras itálicas de la pen ínsula meridional, reprocha, indignado y tajante, a los senadores que desean rendirse a un trato de paz con Pirro, en lugar de continuar la guerra con él; de su gran experiencia y, a pesar de ser viejo y ciego, ..." is non dubitavit dicere illa, quae versibus persecutus est Ennius:

Quo vobis mentes, rectae quae stare solebant antehac, dementes sese flexere viai?" (10).

Y Roma continúa la guerra. El fragmento permite intuir lo vibrante, apasionada y enérgica que debió de ser la oración de un hombre romano puro y coherente con sus ideales patrios, autor del famoso verso "Est unus quisque faber ipse suae fortunae".

Seleccioné tres de los oradores mencionados por Cicerón en el Brutus, "viri diserti" en su mayoría. Hablan "cum auctoritate tum oratione"; poseen el máximo don de la "suaviloquentia"; el de más éxito es "Flos delibatus populi" y "Suadae medulla". No nos cabe ninguna duda de que, a pesar de algunos juicios, a veces "exaltados" de Cicerón hacia sus preferidos antepasados, en esta época de oratoria primitiva, era muy valiosa la correcta participación del orador en la vida política, su experiencia, y, sobre todo, su autoridad moral, para que el discurso llegara penetrante y eficaz hasta los oyentes. "Los antiguos estudiaron el arte de la oratoria a lo largo de muchos siglos. Durante ese tiempo, descubrieron infinidad de hechos sobre la psicología aplicada, la fuerza de la propaganda, la relación existente entre artificio, pensamiento y emoción, y el empleo de la lengua hablada. Pero todos estos hechos, que llegaron a integrar una tradición general de preparación retórica, se perdieron durante la edad oscura. Los hombres hacen sus discursos hoy, y todavía influyen en el ánimo de sus oyentes; pero no pueden calcular sus resultados con tanta seguridad, y los discursos mismos dejan una huella mucho menos profunda que los de los grandes clásicos, porque las reglas del oficio se han olvidado" (11).

\section{PERIODO ARCAICO (240-80 a.C.)}

Es importante hacer una reflexión sobre esta época de la cultura romana por lo que a su literatura se refiere: cuando la poesía ya se expresa con el teatro de Plauto como un producto artístico, la prosa espera aún su gran intérprete. En Grecia, se había presentado el mismo fenómeno, así como sucedió para la oratoria. "Maestros espontáneos" de los oradores parecen ser primeramente los poetas: En Grecia, Homero es considerado el "precursor" de la elocuencia (12); en Roma, no es arriesgado ver en el teatro de Plauto "el género poético más oratorio, en cuanto en él domina la palabra y la acción" (13). Los acontecimientos políticos constituyen, sin embargo, como en la época anterior, el marco ideal para la intensificación del discurso deliberativo y judicial.

Abiertos totalmente los horizontes hacia Grecia, no tarda en ingresar a territorio romano la enseñanza de la retórica en escuelas dirigidas por maestros griegos. La repulsión hacia estas tuvo gran resonancia, pues hasta el senado intervino con 
un decreto del 161 a.C. vetando la permanencia y la propaganda en territorio romano de los maestros de retórica y filósofos griegos. iEs que el romano había aprendido el arte de "su" oratoria en la plaza pública, y no sentía aún la necesidad de darle normas más precisas! "Rhetoricare" y "philosophare" eran los nuevos verbos latinos que expresaban con desprecio la animadversión hacia tales ocupaciones, las cuales, por cierto, sintieron los romanos, algo celosos también de su cultura, por largo tiempo, más aún si consideramos que, en el 92 a.C., otro decreto iba a castigar a los mismos maestros romanos de retórica, considerándose que sus enseñanzas eran "escuelas de impudencia".

Por tal actitud no hay producción alguna sobre el arte que dicta las normas de la oratoria y de la prosa en general, hasta Cornificio y Cicerón, en el siglo I a.C.

Nadie mejor que Catón expresa su hostilidad hacia la retórica: el discurso se escapa a la preceptiva: "rem tene, verba sequentur", el procedimiento del "bonus orator", quien se privilegia de la virtud de hacer derivar dialécticamente el fluir de las palabras desde el amplio conocimiento de las "res", sin una elaborada preocupación por la expresión. Catón es uno de los "hombres ilustres" de la romanidad: de acaudalada familia plebeya, es agricultor y abogado; en Roma, no tarda en inmiscuirse en política y en ejercer varios cargos, de los que consigue autoridad: cuestor, cónsul, censor. Hombre austero, rudo, defensor delos viejos principios que regían la primitiva sociedad romana, ataca, contraponiendo su conducta, las intrigas políticas, el mal gobierno de los magistrados, y el abuso del poder, así como todos los excesos de la aristocracia. La fuerza de su carácter, sin lugar a dudas, se refleja en su prosa, cultivada en Roma por un hombre que pose ía todo, "praeter hanc politissimam doctrinam transmarinam atque adventiciam"' (14): esa doctrina era la predicada por la retórica y la filosofía griega. Y, si bien a su hijo Marco le sugiere que es bueno mirar pero no profundizar, "inspicere, non perdiscere", quedó su prosa influenciada por la preceptiva griega, directa o indirectamente. Sus "Orationes", conservadas en escasos fragmentos, resienten la solemne elocuencia de Demóstenes y Tucídides, según opinión también de Cicerón, Cornelio Nepote y Plutarco. De otra parte, su prosa, si bien sellada por su naturaleza, es tan rica en figuras retóricas, aliteraciones, onomateleutos, políptotos, anáforas, y a veces tan ampolosa como la oratoria tardía que, en realidad, sin conocimiento de la retórica griega, sorprenderían en el primer prosador de la literatura latina: se citan, entre otros, estos pasos más gustados a los estudiosos para confirmar lo anterior: "...tuum nefarium facinus peiore facinore operire postulas, succidias humanas facis, tantum trucidationem facis, decem funera facis, decem capita libera interficis, decem hominibus vitam eripis indicta causa, iniudicatis, incondemnatis...". Pretendes encubrir tu horrible delito con un delito peor, preparas carnes humanas, haces tanto esterminio, preparas diez pompas fúnebres, destruyes diez vidas libres, quitas la vida a diez hombres por una causa no declarada, sin juicio, sin condena" (15).

..."Sé cómo, generalmente, cuando los negocıos son prósperos, provechosos y felices, el ánimo de la mayoría de los hombres se exalta, y su orgullo y su audacia crecen y aumentan. Por ello siento gran inquietud, al ver afirmarse con tanta plenitud nuestro florecimiento, no sea que nuestras resoluciones nos acarrean alguna desgracia que dañe nuestra prosperidad y que la superabundancia de nuestro regocijo no nos lleve a funestos excesos. La adversidad domina y enseña lo que hay que hacer. La prosperidad, a causa del júbilo, desvía nuestras decisiones y nuestro juicio" (16).

Su oratoria de ataque y de autodefensa, expresión de una amplia gama de situaciones graves de la historia de Roma, es una manifestación digna de la prosa latina arcaica: de acción; vigorosa, agresiva...

La hostilidad del ambiente, y de Catón en particular, hacia la filosofía y la retórica no impiden, sin embargo, que éstas se conviertan, paulatinamente, en disciplinas famosas para la formación del romano, sobre todo de clase culta. El acercamiento a ella parece obvia exigencia de madurez cultural: el intelectual-político romano no podía desconocer el valor de la filosofía para disciplinar el pensamiento, y el de la retórica para perfeccionar con sus técnicas el discurso oratorio, el cual se insinúa siempre con más fuerza en la actividad política. Aún no, por supuesto, con la visión amplia de Cicerón.

De probada preparación retórica, alrededor del 130 a.C., es la oratoria de Gaio Graco. Heredero de nobles padres, se cimenta, como el hermano muerto por la oposición, en una empresa de amplias proporciones para su época: su visión política, partiendo de una reforma agraria, lo llevaría de no ser muerto él también, a su sacudir a la república romana desde su íntima constitución, revolucionando el poder de las fuerzas políticas y dominadoras: un gran proyecto que tenía que acabar en sangre. 
Los fragmentos de sus discursos son reflejo de su convicción política, de la sinceridad de sus actuaciones, $y$, para lo que nos interesa, del dominio de las técnicas adquiridas del discurso. Su oratoria es una constante y dramática manifestación de las tantas intrigas políticas y de las malas conductas de los gobernantes. El momento histórico es de extremo "pathos"; se "siente" el presagio de algún acto de violencia: Gaio Graco recurre a todas las técnicas retóricas para persuadir a su público; un público numeroso, por cierto, que lo seguía, cautivado por su elocuencia. Cuando tiene pruebas para demostrar sus acusaciones, esas pruebas, objetivas - "extrínsecas" como codifica la retórica en su primera parte: "inventio", las ofrece con riqueza de detalles y con las figuras que resultan más eficaces para su fin: "Con un solo ejemplo os mostraré a que arbitrariedades y excesos se entregan esos jóvenes. En estos últimos años, traían de Asia a un joven que aún no había desempeñado ninguna magistratura, pero actuaba como legado. Lo traían en una litera. Le salió al encuentro un boyero de Venusa, que, en broma (no sabía con quien trataba) preguntó si llevaban un muerto. EI mandó detener la litera y ordenó empuñar las correas y dar de palos al hombre hasta darle muerte" (17).

Cuando se ve obligado a convencer mediante deducción (entimema), se vale entonces de pruebas sujetivas o "intrínsecas" que su fluida elocuencia transforma en persuasión: "Porque, Quírites, si ponéis cuidado y atención, por más que busquéis, no encontraréis entre nosotros a nadie que venga aquí sin esperanzas de obtener un beneficio. Todos nosotros, los que hablamos, aspiramos a algo, y nada, sino el deseo de una ganancia, impulsa a nadie a acudir antes vosotros. Yo mismo, que os hablo para acrecentar vuestros negocios públicos y facilitar el progreso de vuestros intereses y de los Estados no acudo a la tribuna por nada; es cierto que no os pido dinero, pero sí buena reputación y honra" (18).

Las más clásicas figuras retóricas (antítesis, anacoluto, isocolon entre otras) están presentes en su prosa: "Es imposible ocasionar el deshonor de las personas honradas al honrar a los indignos". "Tu niñez cubrió de vergüenza a tu juventud; tu juventud, de deshonor a tu vejez; tu vejez, de infamia a la patria" (19).

La dramatización de los hechos es también una técnica experimentada de la oratoria, cuando el convencimiento se logra mediante la conmoción (el "movere" de la retórica). Gaio Graco excita el "pathos" de los oyentes al pronunciar, en un mo- mento desesperado quizás, sus últimas palabras: "Quo me miser conferam? Quo vertam? In Capitoliumne? at fratris sanguine redundant. An domum? matremne ut miseram lamentantem videam et abiectam?": " iA dónde ir, desdichado? iA dónde dirigirme? ¿Al Capitolio? Está húmedo de la sangre de mi hermano. ¿A casa? ¿Para ver a mi pobre madre hundida en lágrimas y abandonada? " (20). Cicerón señala como estas palabras fueron pronunciadas con tal mirada, voz y gestos, que provocaron el llanto de los mismos enemigos. Bien observados por Gaio Graco, debían de ser todos los planteamientos de la "actio", la cuarta parte de la retórica, que instruye sobre todos los secretos del convencer con las palabras y la actuación: Cicerón y Quintiliano refieren que tal era su preocupación por la obediencia a estos preceptos, que en todo discurso se hacía acompañar por un esclavo quien le marcaba, con un sonido convencional de la flauta, el ritmo de su voz corrigiendolo así, cuando parecía muy excitado o apagado. Su estilo colorido, variado, rico en figuras retóricas, a los aticistas romanos les pareció demasiado asiano, pero quizás sea mas bien el peculiar estilo de Gaio Graco el de una oratoria juvenilmente culta y apasionada: distante de la de Catón, así como de la Cicerón. "Eloquentissimus" fue considerado por este último entre los hombres de la antigüedad, y nadie "plenior aut uberior" que él; el máximo orador romano apreciaba en sus frases la magnilocuencia, en los pensamientos, la sabiduría, y en todo, la "gravitas" romana (21).

La tradición de Gaio Graco, pervive, en la Europa de la Revolución Francesa, en los hermanos Chenier: Andrés, víctima de ésta, y Marie Joseph, autor, en 1792, de la tragedia en tres actos Gaius Gracus. El drama alcanza fama por el móvil político más que por razones artísticas; tanto es así, que la constitución post-revolucionaria ordenó su presentación tres días a la semana. En Italia, Vincenzo Monti, en 1788, se inspira en el mismo tema para su drama en cinco actos; lo modifica con un desenlace de suicidio por parte de Graco, acusado del homicidio de Escipión el Africano. En la historia de la música, también, el episodio inspira la creación de una obra homónima por Leonardo Leo, en 1700 (22). "Cuando la historia de la república fue concluida, ellos, los Gracos, siguieron viviendo, no como oradores celebrados por todos, sino como ciudadanos condenados por muchos: y de esta condena ellos derivaron una perenne razón de vida" (23). 
(En el próximo estudio presentaré algunos momentos de la oratoria de Cicerón y de le época postciceroniana).

\section{NOTAS}

(1) Charles Bally: El lenguaje y la vida. Ed. Losada, Buenos Aires, 1972, pág. 29.

(2) Ibid.: pág. 29.

(3) Dionisio de Halyc.: Antiquitates Romanae, VI, 49, 2.

(4) Catón: fragmento, Libri ad Marcum filium, conversado por Quintiliano, Institutiones oratoriae, XII, I, 1.

(5) Livio; Ab urbe condita libri, II, 32, 8.

(6) Valentí Fiol: Primera antología latina, Ed. Bosch, Barcelona, pág. 17.

(7) Cicerón: De oratore, 1, 31, 138.

(8) Isidoro: Origines, 2, 1, 1.

(9) Livio: ib íd., II, 41.

(10) Cicerón: De senectute, 6, 16.

(11) G. Highet: La tradición clásica, F.C.E., México, 1954 , t. II, pág. 418.

(12) M.E. Conejo: Revista de Filología y Lingüística, Universidad de Costa Rica,Vol. XI, No. 1, enerojunio 1985 .

(13) C. Marchesi: Storia della letteratura latina, Ed. Principato, Messina, 1973, t. 1o., pág. 147.

(14) Cicerón, ibíd., III, 33, 135.

(15) E. Marmorale: Cato Maior, Ed. Laterza, Bari, 1949, pág. 154.

(16) Fragmento del "Discurso a los Rodios", Historicorum Romanorum Reliquiae, I, Catón, 95, transcripto por: J. Bayet, Literatura latina, Ariel, Barcelona, 1972, pág. 91.

(17) Fragmento 46, Malcovati, de "Oratio de legibus promulgatis”, en J. Bayet, ibíd., pág. 121.

(18) Fragmento 41, Malcovati, de "D issuasio legis Aufeiae", en J. Bayet, ibíd., pág. 121.

(19) Fragmentos 23, 60, Malcovati, en J. Bavet, ibíd., pág. 121.

(20) Cicerón: ibíd., III, 56, 214.
(21) Cicerón: Brutus, 33, 125, 126.

(22) Laffont-Bompiani: Dictionnaire des oeuvres de tous les temps et de tous les pays, t.l: A-Dh, Ed. Societé d'Ėitions de Dictionnaires et Encyclopédies, Paris, 1953.

(23) C. Marchesi, ibíd., pág. 178.

\section{BIBLIOGRAFIA}

(Obras de consulta básica: Cicerón: Brutus y De oratore.)

Bally, Charles. El lenguaje y la vida. Ed. Losada, Buenos Aires, 1972.

Balsdon, J.P. V. D. Los romanos. Ed. Gredos, Madrid, 1970.

Barthes, Roland. Investigaciones retóricas I. La antigua retórica. Ed. Tiempo Contemporáneo.

Bayet, Jean. Literatura latina, Ed. Ariel, Barcelona, 1972.

Bignone, Ettore. Introduzione alla filologia classica. Ed. Marzorati, Milano, 1951.

Curtius, Ernst. Literatura Europea y Edad Media Latina. Fondo de Cultura económica, México, 1975.

Daremberg-Saglio. Dictionnaire des antiquités grecques et latines. Ed. Picard, París, 1946.

Funaioli, Gino. Studi di letteratura antica. Ed. Zanichelli, Bologna, 1951.

Highet, Gilbert. La tradición clásica. Fondo de Cultura Económico. México, 1954.

Laurand, L. Manuel des études grecques et latines. Ed. Picard, Paris, 1946.

Lausberg, Heinrish. Manual de retórica literaria. Ed. Gredos, Madrid, 1970.

Marchesi, Concetto. Storia della letteratura latina, Ed. Principato, Messina, 1973.

Paoli, Ugo E. Urbs. La vida en la Roma antigua. Ed. Iberia, Barcelona, 1973. 